\title{
Literature Review of Management System Frameworks for CSR and Other Sustainability Concepts
}

\author{
Pek Yew Liew ${ }^{1} \&$ Christoph Luetge ${ }^{1}$ \\ ${ }^{1}$ Peter Loescher Chair of Business Ethics and Global Governance, Technical University of Munich, Munich, \\ Germany \\ Correspondence: Christoph Luetge, Peter Loescher Chair of Business Ethics and Global Governance, Technical \\ University of Munich, Arcisstrasse 21, 80333 Munich, Germany. Tel: 49-89-2892-5130.
}

$\begin{aligned} & \text { Received: October 10, } 2018 \\ & \text { Accepted: November 8, } 2018 \quad \text { Online Published: November 25, } 2018 \\ & \text { doi:10.5539/jms.v8n4p22 }\end{aligned}$ URL: https://doi.org/10.5539/jms.v8n4p22

\begin{abstract}
This paper presents an overview and analysis of plan-do-check-act (PDCA) based management system frameworks and other similar structured frameworks that were developed for the systematic implementation and management of corporate social responsibility (CSR), corporate sustainability (CS) and sustainable development (SD). With the aim of providing a comprehensive insight to support future research on this topic, this paper focuses on uncovering the different systematic approaches that can be adopted for the implementation and management of these stakeholder concepts at the organizational level. Our extensive literature search for articles that were published between 2000 to 2017 was able to identify only nineteen relevant articles, which indicates that there is very limited research in this field of work. Our analysis of the frameworks revealed that diverse approaches were developed for CSR. Apart from the traditional management system approach that are based on ISO 9001 (quality management standard) or ISO 14001 (environmental management standard), a variety of other approaches such as frameworks that are built on ISO 26000 (social responsibility guidance standard), organizational change management theories as well as other concepts that are similar to the PDCA cycle were developed for CSR. In contrast to the approaches for CSR, the frameworks that were developed for the implementation and management of CS or SD are mainly based on ISO 14001.
\end{abstract}

Keywords: corporate social responsibility, literature review, management system framework, PDCA cycle, sustainability, sustainable development

\section{Introduction}

Management systems have a long history in the world of business, particularly specific ones such as management systems for ensuring the quality of products and services as well as for the management of environmental, health and safety (Argandoña, 2004). However, despite the proliferation of function specific management system standards (MSS) at the international level, there is to date no internationally recognized MSS for the systematic implementation and management of broad concepts such as Corporate Social Responsibility (CSR) and other related concepts such as Corporate Sustainability (CS) and Sustainable Development (SD). ISO 26000 which was launched in 2010 is currently the only internationally recognized guidance standard for CSR but it does not discuss any requirements for CS/SD. Apart from this, it is not a MSS and cannot be certified (International Organization for Standardization [ISO], 2010). In the absence of a MSS that prescribes requirements for a systematic approach, it is difficult to implement and manage CSR and CS/SD effectively at the organizational level (Singh, Murty, \& Gupta, 2007; Asif, \& Searcy, 2014). This is because these concepts cover a broad spectrum of issues which needs to be managed with a long term perspective and require the engagement of multiple stakeholders from within and beyond the boundaries of the organizations. In fact, these concepts require a paradigm shift in the way businesses operate (Azapagic, \& Perdan, 2003). In order to cope with these challenges, organizations need a systematic approach that focuses on organizational structures, infrastructures and behavior patterns. The approach should be repeatable and uses data and information to enable learning. It should also build in the opportunity for evaluation, improvement, innovation, and knowledge sharing, thereby a gain in maturity (Education Criteria for Performance Excellence [ECPE], 2011; Asif, \& Searcy, 2014). According to Pojasek (2012b), the most straightforward approach is to adopt a management system structure that has a PDCA focus. The continuous and repetitive feature of PDCA cycle provides an excellent means to drive 
continuous improvement towards achieving not only short term goals but also long term goals. This is imperative as the challenge of implementing and managing CSR and CS/SD requires the organizations to contribute to a better quality of life today without compromising the quality of life of the future generations (Azapagic, 2003). In addition, the consecutive planning, implementation, checking, reviewing and improvement activities of the PDCA-based management system approach provide the organizations with a structured framework that not only systematically address the different (sometimes divergent) expectations of multiple stakeholders for a broad scope of CSR or CS/SD related issues, but also accommodate the dynamic changes in today's highly competitive business environment. As the PDCA cycle is a common basis of many widely adopted MSSs such as ISO 9001 (quality management), ISO 14001 (environmental management), OHSAS 18001 (occupational safety and health management), SA 8000 (social accountability) and many others, this similarity provides the organizations with greater confidence in adopting a PDCA-based management system approach for CSR and CS/SD (Asif, \& Searcy, 2014). The PDCA focus of such management system approach facilitates an easier integration into the organizational structure as well as an easier integration with other management systems for a more efficient and effective management (Asif, \& Searcy, 2014; Azapagic, \& Perdan, 2003; Azapagic, 2003). According to Maas and Reniers (2014), there are three main pathways to develop a management system framework for concepts such as CSR or CS/SD. Apart from expanding a Total Quality Management System towards a management system for CSR or CS/SD, the second and rather common pathway is to integrate a variety of MSSs such as ISO 9001, ISO 14001, OHSAS 18001, SA 8000 and many others to form an integrated management system basis for the implementation and management of CSR or CS/SD. Literature reviews on the integrated management system approach for CSR and CS/SD were conducted by several researchers such as Asif, Searcy, Zutshi and Ahmad (2011), Asif, Searcy, Zutshi and Fisscher (2013) and Liew and Lütge (2016). The last and third pathway is about the development of management systems based on specific standards and guidelines for CSR or CS/SD. However, past research and literature reviews on this approach are scarce. In order to fill this gap, this article aims to provide a comprehensive overview and analysis of past research that focused on the development of management system frameworks specifically for CSR or CS/SD. The remaining sections of this paper are organized as follows. Section 2 outlines our approach for literature search, selection and analysis. This is then followed by the Results and Discussion sections. This paper concludes with a summary of findings, research gaps and the potential avenues for future research.

\section{Method}

In order to obtain as many relevant articles as possible, we adopted a broad literature search strategy. For this purpose, we performed a keyword based literature search in several major online databases such as EBSCO's Business Source Premier and Web of Science, Springer Link (http://link.springer.com), Emerald Insight (http://www.emeraldinsight.com), Science Direct (http://www.sciencedirect.com), Wiley Online Library (http://onlinelibrary.wiley.com), JSTOR (http://www.jstor.org/), Taylor and Francis Online (http://www.tandfonline.com), subito_Document delivery service of research libraries in Germany, Austria and Switzerland (http://www.subito-doc.de), SCOPUS (http://www.scopus.com) as well as the web search engine for academic articles, Google Scholar. The keywords that were selected for our literature search include corporate social responsibility, sustainability, sustainable development, management systems, ISO 9001, ISO 14001, OHSAS 18001, SA 8000 and ISO 26000. Different search strings were then built from the different combinations of keywords and Boolean search operators (such as and, or). Despite the broad literature search strategy in at least ten online databases, our literature search has resulted in only several hundred hits.

Secondly, the titles, abstracts and texts of all these articles were briefly reviewed to determine if the content of the articles is relevant for our scope of research. In general, only articles that meet all of the following selection criteria are selected for our literature review.

- The articles must be in English.

- The articles must either be published in peer-reviewed, professional or conference proceedings journals.

- $\quad$ The articles must be published between 2000 and 2017.

- The articles must provide a management system framework/model or a structured approach for the systematic implementation, integration and management of CSR or CS/SD. Most importantly, these frameworks, models or approaches must be based on the PDCA cycle or concepts that are similar to the PDCA cycle or based on any of the international MSSs such as, but not limited to, ISO 9001, ISO 14001, OHSAS 18001 and SA 8000 or international ISO guideline for CSR such as ISO 26000.

In order to be thorough, we have also conducted a final literature search on articles that were cited in the reference lists of the selected articles. When necessary, other publications (i.e. book publications) of the 
respective researchers were used to supplement the articles that were selected for this review. In the final step of our approach, the content of the selected articles were thoroughly reviewed and analyzed to uncover the different approaches that were developed for the implementation, integration and management of CSR and CS/SD, as well as their similarities and differences. For the purpose of simplicity and clarity, the term management system framework is mainly used throughout this article to represent other related terms or names of the frameworks/models.

\section{Results}

This literature review is a review of seventeen management system frameworks for CSR and CS/SD but is based on a total of nineteen articles (instead of seventeen). This is because one of the management system frameworks was described in a series of three articles and this framework was published by Pojasek in 2012. Despite the proliferation of publications on CSR and CS/SD in the last decades, our research revealed that there are only very few researchers who specifically explored the development of management system frameworks or systematic approaches for the implementation and management of CSR and CS/SD. This is consistent with the findings of Asif and Searcy (2014), Maon, Lingreen and Swaen (2009) and Singh et al. (2007). Based on our statistical analysis as shown in Figure 1, the enthusiasm for the development of management system frameworks for CSR and CS/SD is mainly observed between 2003 and 2006. However, only very limited interest is shown in the development of such frameworks for both CSR and CS/SD in the last decade.

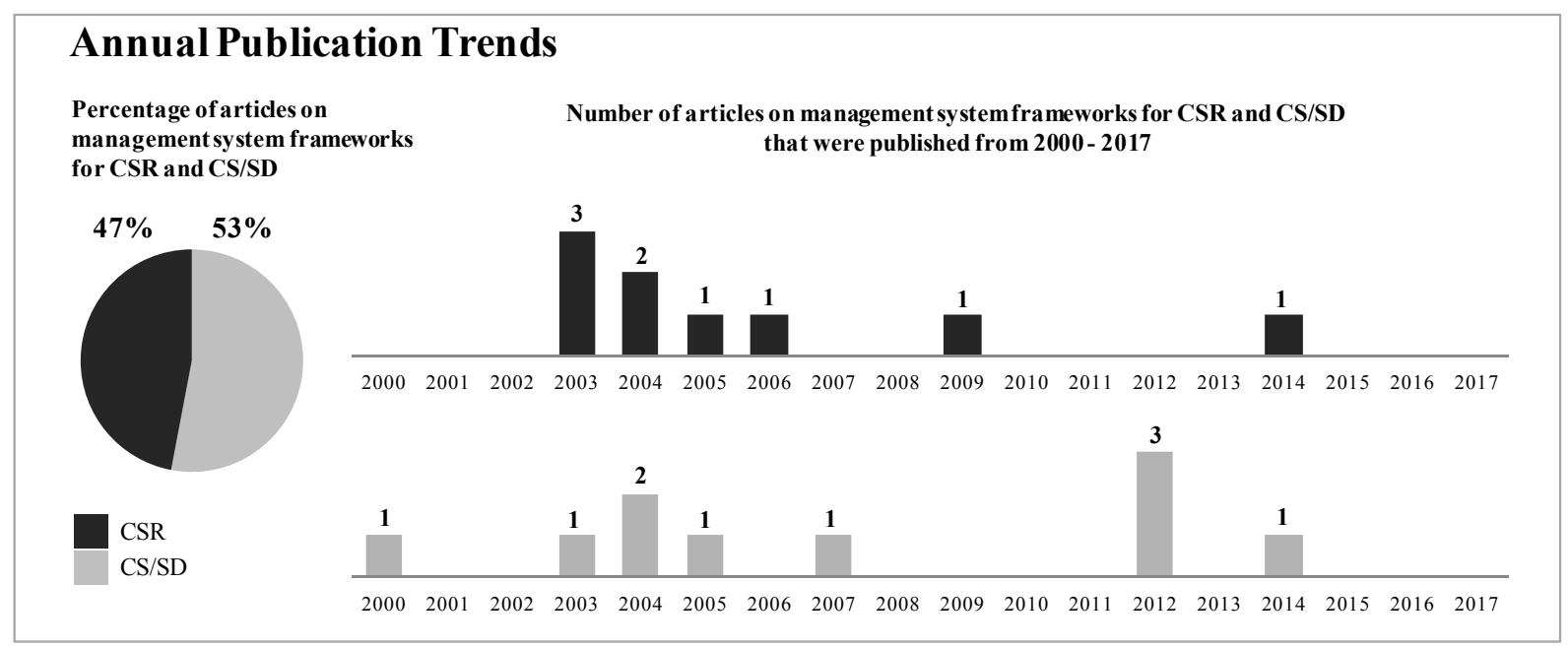

Figure 1. Annual publication of articles on management system frameworks for CSR and CS/SD

The articles that were selected for this literature review were published diversely across twelve journals as listed in Figure 2. Approximately $79 \%$ of the selected articles were published in peer-reviewed journals, $16 \%$ in professional journals and 5\% in conference proceedings journals. However, for a more comprehensive understanding of one of the management system frameworks, we supplemented the article that was published by Castka, C.J. Bamber, D.J. Bamber and Sharp in 2004 with a book publication of these researchers (refer to Castka, C.J. Bamber and Sharp (2004b)). 


\section{Types of Journals}

Percentage of the different types of journals
in which the selected articles were published

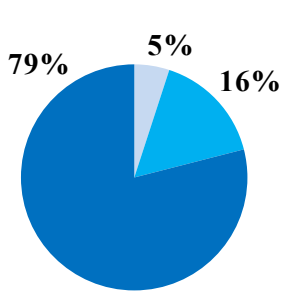

Peer-Reviewed Journals

Journal of Business Ethics (4)

Journal of Cleaner Production (2)

The TQM Journal / The TQM Magazine(2)

Greener Management International (2)

World Review of Entrepreneurship, Management

and Sustainable Development (1)

Trans IChemE(1)

International Joumal of Corporate Sustainability (1)

Eco-Management and Auditing (1)

European Journal of Marketing (1)

Professional Journals

Environmental Quality Management (3)

Conference Proceedings Journals

Environmental Economics and Investment

Assessment(1)

Peer-Reviewed Journals

Professional Journals

Conference Proceedings Joumals

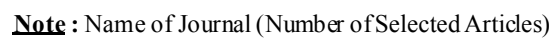

Figure 2. Statistical overview of the types of journals

Apart from that, $58 \%$ of the articles that were selected for this literature review are conceptual articles; $5 \%$ of these articles are case study articles and the remaining $37 \%$ are research articles that adopted a combination of research methods such as a combination of conceptual and case studies or conceptual and empirical approaches. Our statistical analysis in Figure 3 also shows that majority of the selected articles for CS/SD (approximately $80 \%, 8$ out of 10 articles) are conceptual ones. This is however not the case for articles on CSR where only $33 \%$ of the selected articles for CSR are conceptual ones. Majority of the researchers (approximately $67 \%, 6$ out of 9 articles) adopted a combination of research methods for the development of the management system frameworks for CSR.

\section{Types of Research Articles}

Percentage of the different types

of research articles

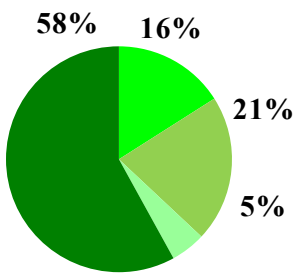

Conceptual Articles

Case Study Articles

Conceptual and Case Study Articles

Conceptual and Empirical Articles
Number of selected articles for each type of research article

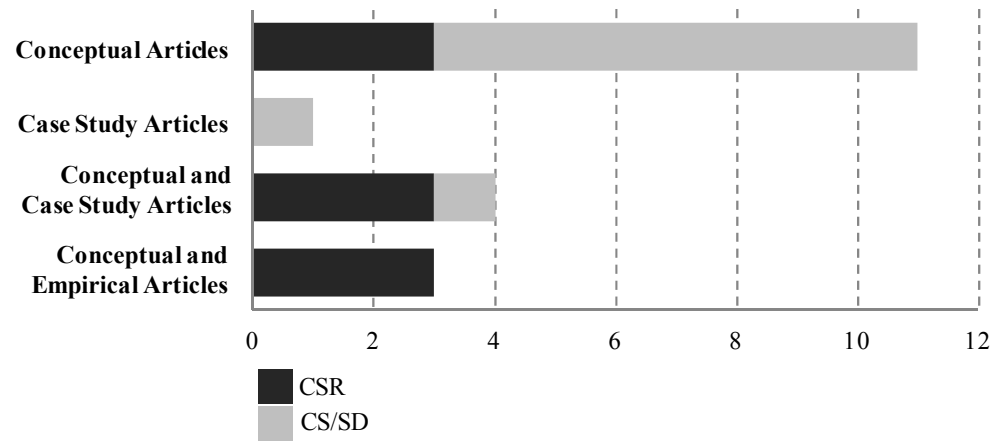

Figure 3. Statistical overview of the types of research articles

\section{Discussion}

All of the management system frameworks that were selected for this literature review are based on the PDCA cycle of continuous improvement (or similar concepts to the PDCA cycle), which means that all the frameworks have the basic foundation (that comprises consecutive planning, implementation, checking, reviewing and continuous improvement activities) for the systematic implementation and management of CSR or CS/SD. These frameworks have a similar core approach that focuses on setting and achieving objectives and targets that are determined based on the identification and assessment of relevant and significant CSR or CS/SD issues. 
Subsequent action plans and programmes that are derived to achieve these objectives and targets help the organization to translate the relevant CSR or CS/SD requirements into concrete actions, integrate them at the organization level, improve the organization's overall CSR or CS/SD performance as well as continuously monitor and improve to achieve the organization's long term mission and vision. However, each of these frameworks has a slightly different emphasis and they differ in the elements that constitute the management systems for CSR or CS/SD. Apart from that, as stakeholder management is central for CSR and CS/SD, many aspects of stakeholder management are covered by the frameworks but the scope varies from framework to framework. Our selection of frameworks ranges from comprehensive frameworks that possess similar elements to the ISO based management systems to simple approaches for CSR and CS/SD. The details of the different approaches will be discussed in the following two subsections.

\subsection{Management System Frameworks for CSR}

Nine of the selected management system frameworks were developed for CSR and a concise overview of these frameworks is presented in Appendix A (see Table A1 and Table A2). Management system frameworks that were developed by Argandoña (2004), Castka et al (2004a; 2004b) and Azapagic and Perdan (2003) are the three most comprehensive frameworks for CSR. They have a similar structure as the ISO-based management systems but strong emphasis on stakeholder management. Some of the common stakeholder related elements that are observed in all three frameworks include elements for the identification of relevant stakeholders and their requirements, assessment of related issues and organizational impacts, systematic integration of stakeholder requirements into organizational processes and structure, communication with stakeholders, involvement and engagement of stakeholders. Unlike other frameworks for CSR that usually only focused on the management of the triple bottom line (economic, social and environmental issues), Argandoña (2004) included ethical responsibility into the scope of his management system framework. In this ethical, social and environmental management system framework, the core focus is on the integration of relevant stakeholder requirements into ethical code of conduct, internal policies and procedures that are used to standardize, control, monitor, review and improve processes, as well as to mould and sustain the ethical behavior of the management and employees with the aim of achieving the organization's ethical, social and environmental goals. The importance of involving relevant stakeholders and allowing them to take a share of responsibility at certain stages of this framework such as drafting of code of conduct, identification of processes that are affected by the management system, training of employees and implementation of continuous improvement processes as well as nurturing of employee and managerial commitment was also highlighted by Argandoña (2004). As ethical management is an ongoing process that should grow continuously, the continuous improvement element of this management system is imperative in this respect to support the organization in adapting to the changes that arise from the external environment as well as to the changes from within the organization that arise from implementing the ethical, social and environmental programmes, such as those that are related to the organization's culture and values (Argandoña, 2004).

Based on the result of extensive research, Castka et al. (2004a; 2004b) developed a process-based CSR and Corporate Governance (CG) management system framework that is analogous to the ISO 9001:2000. According to Castka et al (2004a; 2004b), corporate governance should be an integral part of a CSR management system because the senior management or board of directors sets the strategic direction of the organization, provide the necessary resources and must therefore be held accountable for the impacts of their decision. The main difference between this $\mathrm{CSR} / \mathrm{CG}$ management system and other management system frameworks is the distinctive elements for corporate governance. In this framework, the role and responsibilities of the senior management or the board of directors are clearly specified for the implementation and management of CSR. Even the strategic plans that include the objectives, targets and indicators of CSR/CG must be approved by the board of directors before it can be cascaded down to different processes and different levels of the organization. Central to this framework is the integration of stakeholder requirements into business strategy and the organization's processes to improve the balance between entrepreneurship and the demands for CSR from stakeholders (Castka et al., 2004a; Castka et al., 2004b). Apart from that, specific elements for managing change and ensuring continual improvement are also included in this framework. These elements focus not only on the continuous improvement of the CSR/CG management system but also on the development of an organizational culture that is responsive to continual change and responsible behavior (Castka et al., 2004b).

Unlike the framework that was developed by Castka et al. (2004a; 2004b), the CSR management system that was developed by Azapagic and Perdan (2003) does not cover elements for corporate governance but they highlighted the importance of clear commitment from senior management and aligning the CSR policy with the business vision and strategy to prevent CSR from being a mere "add on" programme. This framework has a 
similar structure as the ISO 14001 and a similar core approach as the other two frameworks, but it provides a step-by-step guide with recommended methods and examples on how to integrate the principles of sustainable development into business strategy and organizational processes to balance and improve the triple bottom line (economic priorities, environmental objectives and social concerns). For the purpose of setting objectives and targets that are realistic, the authors emphasized on the use of economic, environmental, social and integrated indicators to translate the identified key CSR or sustainability issues into quantitative or qualitative measure of performance. These indicators are not only used to establish a baseline to help the organization to understand where it is starting from and how difficult it is to achieve its CSR or sustainability commitments, but also for the regular monitoring of performance which will provide a good indication of the direction in which the organization is developing - whether towards or away from its CSR or sustainability vision. These indicators are then used as inputs for the identification and evaluation of the organization's internal strengths (S), weaknesses $(\mathrm{W})$, potential opportunities $(\mathrm{O})$ and threats $(\mathrm{T})$ using strategic planning method such as sustainability SWOT analysis, as well as for setting of objectives and targets. The management of cultural change within the organization was briefly discussed by the authors. In this framework, the authors use awareness raising, training, motivation programmes such as (financial and non-financial incentive schemes) and internal/external reporting programmes to facilitate the necessary internal cultural change for driving the organization towards achieving its CSR commitments and long term vision for sustainable development (Azapagic \& Perdan, 2003).

The remaining six management system frameworks for CSR are less comprehensive ones but they provide diverse approaches for the implementation and management of CSR at the organizational level. Avarossis, Panayiotou and Tsousi (2009) presented a simple iterative three stage methodological framework that focuses on the management of the organization's impacts and the conformance to CSR requirements in five categories, namely the environment, society, human capital, shareholders and marketplace (customers and suppliers). In this framework, they combined the external strategic analysis (Political, Economical, Social and Technological [PEST] analysis) with the internal strategic analysis (SWOT analysis) to analyze and define all possible factors that can directly or indirectly affect the strategic orientation of the organization in relation to CSR. Based on these analyses, specific measurable CSR targets are defined and action plans/programmes are developed and executed. In the third and final stage of this framework, the CSR performance in the five defined categories is measured using a multicriteria analysis and weighted performance indicators, and the suitability of the implemented CSR policies and programmes are investigated. In contrast to the framework by Avarossis et al. (2009) that covers a broad scope of CSR issues, the framework that was developed by Panapanaan, Linnanen, Karvonen and Phan (2003) focuses only on the social dimension of the triple bottom line. Panapanaan et al. (2003) only provided a brief description of their approach for CSR but emphasized on the importance of conducting an initial social risk assessment that identifies and assesses the relevant CSR issues and parameters by considering the different stakeholder clusters, namely employees, community, suppliers and customers. Based on this assessment, the organization can then decide whether to pursue with the implementation and management of CSR or not. The implementation and management of CSR itself will require five essential elements of a typical PDCA based management system, namely organization and structure, planning, implementation, monitoring and evaluation and lastly communication and reporting. However, the details of these elements are not elaborated. The frameworks that were developed by Avarossis et al. (2009) and Panapanaan et al. (2003) do cover some forms of identification, assessment and addressing of stakeholder requirements but specific elements for the involvement and engagement of stakeholders are however not included.

The challenges in implementing and managing CSR or CS/SD at the organizational level are not only about the conformance to CSR or CS/SD requirements, but also about how the organization's culture and values need to be changed in order to successfully incorporate CSR or CS/SD into its business agenda and operations (Castka et al., 2004a; Argandoña, 2004). Unlike the typical ISO-based management system that mainly focus on achieving the pre-determined objectives and targets, the management system framework that was developed by Maas and Reniers (2015) goes beyond the limitations of the traditional PDCA cycle and emphasizes on both the rational aspects (elements to achieve the predetermined objectives and targets) as well as emotional or human aspects (elements to anchor a CSR or CS/SD mindset at the organizational level) for the strategic integration of CSR at the organizational level. This framework for CSR (named 'Sus5') is developed based on the threefold challenge of intergrating CSR as described in ISO 26000 and the regulations for ISO-based management systems (ISO Guide 72), with consideration of the double role of stakeholders (both as instigators and receptors of the CSR policy) as well as taking in account of the entire supply chain. This has resulted in a framework that is made up of a set of five interdependent building blocks, namely soft and hard factors of CSR that are connected together in a circular manner by cause and effect relationships. The soft factors (emotional/human aspects of CSR integration) focus on improving the knowledge and commitment of three groups of people, namely the 
management, stakeholders and employees. The hard factors (rational aspects of CSR integration) however refer to the strategic planning stage and operational planning, implementation and monitoring stage of the framework. According to Maas and Reniers (2015), the combined knowledge and commitment from the management and stakeholders lay the foundation for determining the strategic direction and strategic plans. However, the strategic plans can only be translated into operational actions, procedures and process improvements after the levels of understanding, knowledge and commitment of employees in regards to CSR and their role in contributing to achieving the organization's CSR mission and programmes are improved. An accurate evaluation of the implemented actions and the corresponding results by the management and stakeholders will optimally further improve the knowledge and commitment of the management and stakeholders in regards to CSR. The typical elements of a PDCA based management system constitute only part of this framework and these elements belong to the hard factors of the framework. This framework also constitutes other elements for improving and managing the human aspects in CSR integration as well as for the explicit involvement and engagement of both internal and external stakeholders in defining the organization's CSR direction. These soft factors are particularly important because the CSR performance of the organization depends more than ever on the efforts that are made by every individual within the organization and its stakeholders (Cramer, 2005).

The remaining two frameworks by Werre (2003) and Maon, Lindgreen and Swaen (2009) were developed for the implementation and management of CSR from an organizational change perspective. The Corporate Responsibility (CR)-implementation model that was developed by Werre (2003) consists of four implementation phases that must be covered in order to achieve a lasting organizational change. Similar to the framework by Maas and Reniers (2015), the PDCA cycle constitute only part of this model and is adopted only for the purpose of creating and anchoring large scale change in the organizational behavior (which represent phase 3 and 4 of the model for translating vision and values into everyday behavior to achieve the desired organizational change). The author did not provide any details on how the management system for implementing CR should be designed but the adoption of SA 8000 was quoted as an example. Some key elements of a management system and actual implementation experiences of an organization (Chiquita) were also discussed. Prior to the adoption of a management system for implementing $\mathrm{CR}$, the author emphasized on the importance of initially raising the awareness of the top management on core values that are related to CR as well as on the sensitivity to the changes in the organization's external environment that can affect the survival of the organization, which can be achieved through values audit, stakeholder dialogues and scenario analyses. It is only after this phase, that the CR-vision (the long term strategic goals and direction) and core corporate values (the principles that guide decisions and behavior) can be formulated effectively in a carefully designed process to ensure that the vision and values are shared by both the top management and employees. According to Werre (2003), the requirement to obtain a smooth implementation in the organization at large is to start from where the people are. Actions that are not aligned with their values will most likely meet with considerable resistance. In this CR-implementation model, Werre (2003) focused mainly on the importance of internal communication as well as the involvement of internal stakeholders for the successful implementation of CSR programmes. However, he highlighted that it is useful to consult and engage relevant external stakeholders with specific expertise in a particular CSR issue. Apart from this, there are no detailed elements within this model for addressing other aspects of stakeholder management.

In contrast, the integrative framework for CSR that was developed by Maon et al. (2009) provides a more comprehensive approach from an organizational change perspective. On the basis of Lewin's (1951) force field model of change that capture the dynamics (refering to the changes in the equilibrium between the driving forces for change and restraining forces against change) associated with adopting a CSR orientation, a similar concept to PDCA cycle (plan-do-check/improve and mainstream) and multiple case studies involving multinationals such as IKEA, Philips and Unilever, Maon et al. (2009) identified four stages of implementing change which incorporate nine important steps for the development and implemention of CSR in an organization. This framework begins with "sensitize" which is the first stage towards implementing change. In this stage, the CSR awareness within the organization is raised by considering both top-down (top manager awareness which influences the CSR strategy and implementation) and bottom-up processes (awareness of employees and workers who induce their employers to include CSR practices). This is followed by the second stage of implementing change called "unfreeze", which corresponds to the "Plan" step of the "Plan-Do-Check/Improve-Mainstream" cycle. This "unfreeze" stage covers four consecutive steps such as the assessment of the organization's purpose in a societal context, the establishment of a shared vision and working definition for CSR, the assessment of the current CSR status by auditing the current CSR practices and benchmarking and finally the integration of CSR into the organization's strategy and the development of a CSR integrated strategic plan that translates values, visions and policy statements into commitments, expectations and guiding principles. The third stage of 
implementing change is called "Move", which corresponds to the "Do" and "Check/Improve" steps of the "Plan-Do-Check/Improve-Mainstream" cycle. The "Move" stage is about the implementation of the CSR integrated strategic plan, the continuous internal communication about CSR commitments and performance (to improve the awareness of the employees on CSR), the evaluation of CSR-integrated strategies and performance (for the detection, reporting and resolution of any problematic areas and for the improvement of CSR programmes). This stage is then followed by "Refreeze" which is the last stage of this framework and it corresponds to "Mainstream" step of the"Plan-Do-Check/Improve-Mainstream" cycle. The "Refreeze" stage is about anchoring the implemented changes, not only into the organizational systems but also into the organizational culture and values. At this stage, both internal and external communications are important to institutionalize CSR. In summary, this framework builds on the organization's values to create an organizational culture that is receptive to change and can sustain a CSR strategy over a long run. The organizational values and norms guide behaviors and decisions within the organization and they support the organization's efforts to reach its vision and objectives (Maon et al., 2009). Unlike the common approach that covers only three main responsibilities - economic, environmental and social responsiblities, Maon et al. (2009) focused on five key CSR aspects such as the social and environmental dimensions and impacts of the organization's activities, corporate governance, societal dialogue process and corporate commitment to sustainability. This framework covers many aspects of stakeholder management but emphasizes particularly on the continuous involvement and engagement of both internal and external stakeholders throughout all stages of this framework. The approach of this framework is however very similar to the framework that was developed by Maignan, O.C. Ferrell and L. Ferrell in 2005 but the latter framework is less comprehensive and was designed primarily for implementing and managing CSR in marketing - an organizational function that traditionally mainly focused on addressing the needs of the customers. The framework that was developed by Maignan et al. (2005) provides a step by step stakeholder oriented approach for broadening the scope of marketing from customer oriented to stakeholder oriented and this enables the organization to demonstrate a wider organizational responsibility in marketing. In this framework, the organizational values, norms and mission that have implications for CSR are initially identified. This is followed by the identification and assessment of relevant stakeholders based on their power and legitimacy. The level of power and legitimacy of the stakeholders will then be used to determine the degree of urgency in addressing their specific expectations and main issues of concern. Next, the meaning of CSR in terms of marketing is assessed and the current practices are audited to identify the marketing activities that need to be added or improved. Based on the audit results, focus areas are prioritized and implemented with consideration on the levels of financial and organizational investments as well as the degree of urgency. The promotion of CSR is a crucial step after the implementation of CSR. In this step, the organization is required to keep its internal and external stakeholders aware of the CSR initiatives, engage and establish bonds to stakeholders as well as involve them in the organizational CSR initiatives. Lastly, the assessment of the organization's progress in addressing stakeholder issues must be conducted regularly. The feedbacks from stakeholders in this respect provide valuable inputs for the continuous improvement of the CSR programmes.

\subsection{Management System Frameworks for CS/SD}

In contrast to the diverse management system approaches for CSR, the remaining eight management system frameworks that were developed for CS or SD are mainly built on the environmental management system standard, ISO 14001 that is adapted to provide a more balanced approach for the management of the triple bottom line, namely the financial, environmental and social performance. According to Sealy, Wehrmeyer, France and Leach (2010) and Moxen and Strachan (2000), the ISO 14001 standard is in fact the most common means among the standardized management systems for implementing CS/SD. However, as the ISO 14001 standard covers a rather narrow scope that is limited to environmental management, this standard can only provide a starting point for implementing CS/SD but it cannot be a substitute for sustainability management system or sustainable development management system (Asif \& Searcy, 2014). This subsection aims to discuss the different approaches of adapting an ISO 14001 based environmental management system as well as to uncover other elements (apart from the typical core elements) that can be included in a management system framework for an effective and systematic implementation and management CS or SD. Apart from that, a concise overview of these frameworks can also be obtained in Appendix B (see Table B1 and B2). We begin with the four most comprehensive management system frameworks in our selection, which are those that were developed by Asif and Searcy (2014), Pojasek (2012), Singh et al. (2007) and Azapagic (2003). These frameworks have a similar systematic structure as the ISO 14001 standard but they are adapted to focus primarily on the control and management of significant sustainability (economic, environmental and social) risks or issues, which requires the development and implementation of stakeholder oriented programmes such as the identification and assessment of relevant internal and external stakeholders, their requirements and related issues, 
addressing and integration of the relevant requirements into the organization's policies, procedures, processes and services as well as the active involvement and engagement of stakeholders.

Asif and Searcy (2014) developed a very comprehensive sustainable development management system (SDMS) that covers many shortcomings of other management system frameworks for CS/SD in our selection. This framework is built on a hybrid approach that consists of three interrelated parts, namely the descriptive "underlying values and principles of SD" to provide an enhanced understanding of the concept SD and the prescriptive "management system requirements" that are supported by a "hybrid assessment approach" for a more comprehensive evaluation of the organization's performance in SD as well as for sustaining continuous improvement of the SDMS and organization. This SDMS is based on five core values and principles of SD, namely stakeholder oriented management, triple bottom line, systematic approach, strategic management and most importantly the continuous improvement, innovation and learning along all dimensions of stakeholder requirements. The remaining two parts of this framework, referring to the prescriptive management system requirements and the hybrid assessment approach, provide all the necessary structural requirements for an effective SDMS. This SDMS differs particularly in its approach at the Plan, Check and Act stages of the PDCA cycle. At the Plan stage, Asif and Searcy (2014) explicitly bring the attention to some organizational arrangement elements that are included to prepare the organization for an effective implementation and management of SD. These elements include "planning organizational changes" which covers developing of organogram, functions, infrastructure, sustainability policy, mission, vision and strategy, "developing prior competencies for SD", "allocation of required resources such as human, financial, material, informational and infrastructural resources", "securing commitment of top management" as well as "planning how the organization manages risk and what measures must be taken in case of accidents or non-compliances". According to Asif and Searcy (2014), as no single approach will be able to provide a comprehensive assessment of the organization's sustainability performance, they recommended the adoption of an assessment approach that combines three assessment methods, namely audit for compliance, self assessments for achieving excellence and benchmarking. Audits and self assessment focus more on internal assessment. However, benchmarking allows the organization to compare its performance against the industry's best practices (Best-In-Class), which provide more competitive and market-based standards for performance improvement. Benchmarking also allows the managers to think beyond their own organizational setting and this is important for the continuous improvement of the organization in regards to SD (Asif \& Searcy, 2014). Another notable feature at the Act stage of this framework is the specific elements that require the organization to establish systematic approaches to carry out improvements based on past experiences, support learning and integrate the newly acquired sustainability related knowledge into the organizational processes and procedures.

A sustainability management system (SMS) framework for the steel industry was developed by Singh et al. (2007) and it is heavily modeled on ISO 14001 (Asif and Searcy, 2014). Most of the elements of this SMS are similar to the typical environmental management system but they are adapted for the control and management of significant sustainability risks and issues, with the active involvement and engagement of stakeholders. Also included in this SMS are many examples to support the application of this SMS in the steel industry as well as a qualitative assessment tool that was developed by Singh et al. (2007) for the identification and evaluation of significant sustainablity aspects. In this tool, seven criteria are considered, namely the probability of occurance, duration, area and scale of the resulting sustainability impact, degree of legal compliance, controllability of the sustainability impact and concerns of the relevant stakeholders. Pojasek (2012a) presented his version of a SMS that aims to manage sustainability as an important thrust in business management processes and to mainstream sustainability into the existing day to day activities. This SMS has a very similar structure to the ISO 14001 . However, Pojasek suggested the incorporation of elements from other management system standards into the SMS, such as elements from quality management standard ISO 9001 on product/service realization and change management, elements from risk management standard ISO 31000 on the evaluation of risks, determination of how the risks will be handled and controlled during normal and abnormal situations as well as elements from occupational health and safety standard OHSAS 18001 and business continuity management standard ISO 22301 on emergency preparedness and business continuity management (Pojasek, 2012a; Pojasek 2012b; Pojasek 2012c). As the sustainability concept demands for actions over long term, Pojasek (2012c) emphasized the importance of using two types of performance indicators, namely the lagging and leading indicators. Lagging indicators are commonly adopted but they encourage short-term thinking as they focus primarily on results or what has alrealy happened. In order to drive sustainability performance forward, it is necessary for organizations to adopt leading indicators that will focus on improving processes in a way that will lead to favourable results in the future (Pojasek, 2012c). In this framework, Pojasek (2012c) proposed to convert the eight quality management principles that are related to behaviors, values and beliefs (adapted from ISO 9004) into 
quantitative leading indicators and use them to improve the long term viability of the SMS. Another notable feature of this SMS is the adoption of a "systems approach" that can support the organization to systematically create action plans for meeting its sustainability goals and targets. The "systems approach" was developed by Pojasek (2005) and it relies on a number of structured problem-solving and decision-making tools for improving processes with the emphasis on teamwork rather than on individuals. Some of the most important "systems approach" tools include process mapping, rank ordering, Pareto charting, root cause analysis, generating alternative solutions, prioritizing solutions and creating action plans.

Azapagic (2003) also presented a systems approach but this approach refers to a management system approach for the development, management, communication and improvement of sustainability policies in an organization. The systems approach for corporate sustainability or corporate sustainablity management system (CSMS) that was developed by Azapagic (2003) is very similar to the CSR management system (CSRMS) that was developed by Azapagic and Perdan in 2003. Both of these frameworks focus on the translation of sustainability principles into corporate practices and on improving the triple bottom line of the organization. However, the CSMS is the more comprehensive framework with additional elements at each stage of the management system for a more efficient implementation and management of sustainability at the organizational level. In this framework, the sustainability strategy emerges from and is embedded into the business strategy and vision. Comparing this framework with the CSRMS of Azapagic and Perdan (2003), the key notable difference lies at the first stage of this framework where Azapagic (2003) emphasized on the importance of carrying out four important steps before a sustainability policy can be defined and put into practice. These are namely the demonstration of leadership and commitment to sustainability, the identification of threats and opportunities as well as the identification of stakeholders and sustainability issues. The remaining stages of this framework encompass typical management system elements. Many suitable examples were also provided to illustrate how the CSMS can be applied in practice (Azapagic, 2003).

With the aim of making the ISO 14001 standard more comprehensive and effective in assisting organizations in taking concrete steps towards a more sustainable business model, MacDonald (2005) enhanced the planning section of the ISO 14001 standard to include fifteen strategic planning requirements using a "backcasting method". The "backcasting method" is a unique strategic approach that uses an envisioned successful and sustainable future as a starting point for planning. It encourages the organization to view sustainability in a holistic manner which results in the development of comprehensive strategies and concrete efforts that are directed towards achieving the organization's vision from the current state. The remaining three frameworks in our selection are less comprehensive ones and these are frameworks that were developed by Oktem, Lewis, Donovan, Hagan and Pace (2004), McElhaney and Toffel (2004) as well as Klaver and Jonker (2000). Oktem et al. (2004) developed a sustainable management system model that is based on environmental management system principles and best practices that were observed in the chemical, pharmaceutical, petrochemical and transportation industries. This model comprises of five core components such as building a business case, organizational component, operational component, enterprise resource planning/ information technology (ERP/IT) system as well as monitoring and audits. Two of these core components, namely the operational component and the monitoring and audits component, cover most of the typical elements of a traditional management system. According to Oktem et al. (2004), the first organizational challenge is actually to have EHS and SD properly represented by the top management and the board of directors. In order to overcome this challenge, Oktem et al. (2004) emphasized on the importance of initially obtaining management buy-in (through building a business case) and setting up of a clear organizational structure. Another core component of this model is the adoption of a well designed enterprise resource planning/information system (ERP/IT) system to support the processes of this sustainable management system model. The ERP/IT system is able to provide an integrated overview of the business processes (for the organization and its supply chain) and facilitate data collection, management and interpretation. In summary, these three core components are usually not explicitly included as requirements in traditional management systems but they are imperative for the effective implementation, maintenance and continuous improvement of the sustainable management system model. Oktem et al. (2004) also included four case studies in their article to demonstrate the different approaches for implementing this model.

McElhaney and Toffel (2004) presented a case study that describes how an industrial design company (wholly owned by BMW Group) developed and implemented a sustainability management system (SMS) from an ISO 14001 based environmental management system. In general, the scope of the environmental management system was extended to include social and economic aspects for sustainability management. However, McElhaney and Toffel only provided a brief description of the SMS but they discussed the five implementation phases of the 
SMS and shared the specific outcomes and challenges of the implementation process, including the experiences of working with both internal and external stakeholders such as suppliers, contractors, customers and employees. According to Klaver and Jonker (2000), although the ISO 14001-based or Eco-Management and Audit Scheme (EMAS) based environmental management systems are widely adopted, they are lagging behind the changes in the society. Therefore, Klaver and Jonker (2000) proposed the development of a new environmental management (NEMS) that will enable organizations to adapt and respond adequately to the changes in the society as well as make positive contributions to SD. However, Klaver and Jonker (2000) did not provide any conceptual framework but they highlighted that the NEMS must have eight important requirements that covers topics such as the awareness to the changes/development in the society through environmental scanning, internal and external stakeholder engagement and the importance of managing the differences in values in the organization as because shared values are regarded as the main cement that holds people together and motivates them to either act alone or in coorperation with others. An overview of these eight requirements is provided in Table B2 (see Appendix B).

\section{Conclusion}

The terms corporate social responsibility (CSR) and sustainability / sustainability development (SD) (as well as other sustainability related concepts) are often used interchangeably. However, they are actually different concepts with a very close relationship between them (ISO, 2010). According to our analysis in this literature review, the management system approaches that were developed for the implemention and management of CSR are in fact very similar to the management system approaches for CS/SD. Regardless if the management system frameworks are developed for CSR or CS/SD, these approaches are mainly centered on the management of the triple bottom line (economic, social and environmental issues) as well as on the management of stakeholders and their requirements. As the management of CSR and CS/SD is a gradual and ongoing process (Argandoña, 2004), the PDCA structure of these management system frameworks provides a perfect foundation for the systematic management of these broad concepts at the organizational level as well as for driving the organization to continuously improve and achieve not only its current CSR or CS/SD objectives and targets but also its long term CSR or CS/SD mission and vision. Similar to the approach of the widely adopted ISO 14001 based environmental management systems that focuses on the identification, assessment and management of significant environmental aspects and impacts, the management system frameworks for stakeholder concepts such as CSR and CS/SD also adopt a similar approach but they focus on the identification, assessment and management of relevant stakeholders, their requirements and significant CSR and CS/SD issues. However, the challenges in the implemention and management of CSR and CS/SD are not only about the conformance to CSR and CS/SD requirements, but also about how the organization's culture and values have to be changed and sustained. As the sustainability or CSR performance depends more than ever on the efforts made by three groups of people, namely the management, stakeholders and employees (Cramer, 2005), it is imperative that the organization manages the value differences among these three groups of people. When this aspect is neglected and the opposing value systems are present between these three groups of people, it will be detrimental to the cohesion and the performance of the organization (Klaver and Jonker, 2000). This is in fact the most difficult aspect in the implementation and management of management systems but it is often neglected (Klaver and Jonker, 2000). According to Werre (2003), values are non-explicit principles that are expressed in behavior. Values help people to assess situations and make decisions. Values not only guide the daily actions and decisions, but they also provide the context for strategic business decisions. The dominant values of the management and the rest of the organization determine the manner in which a particular change can be successfully implemented (Werre, 2003). Therefore, we would like to highlight an important managerial implication, namely the need for managers to also focus on the management of values that can be achieved with the support of the PDCA-based management system frameworks. The PDCA focus of such approaches can as well be adopted to systematically develop and sustain the shared values or mutually respected values (which are regarded as the main cement to hold people together and motivates them to act, alone or in co-operation with others; Klaver and Jonker, 2000) and the desired organizational culture. This can be achieved through the identification and assessment of the dominant values as well as the differences with the desired values using values-audit (Werre, 2003). Based on this assessment, the appropriate awareness, training or competency improvement programmes can be identified and implemented to develop the desired shared values and organization culture. Apart from that, in order to determine if the identified and implemented programmes are effective, regular evaluation of the changes in the dominant organizational values and culture should be carried out. It is also important that subsequent actions are taken to sustain the newly developed shared values and organizational culture. A notable gap in the literature is the study on the practical application of these conceptual management system frameworks in real business settings. In the absence of an internationally recognized management system standard for CSR or CS/SD, it will 
be interesting to investigate if management system approaches are actually adopted by organizations for the implementation and management of CSR or CS/SD as well as to uncover how such management system approaches and the associated change management programmes are designed, implemented and effectively optimized for the organizations, their subsidiaries and supply chains.

\section{Acknowledgments}

The authors wish to thank those who have contributed directly and indirectly to the successful completion of this research and publication.

\section{References}

Aravossis, K. G., Panayiotou, N. A., \& Tsousi, K. (2006). A proposed methodological framework for the evaluation of corporate social responsibility. Environmental Economics and Investment Assessment, WIT Transactions on Ecology and the Environment, 98, 87-95. http://dx.doi.org/10.2495/EEIA060091

Argandoña, A. (2004). On ethical, social and environmental management systems. Journal of Business Ethics, 51(1), 41-52. http://dx.doi.org/10.1023/B:BUSI.0000032350.51151.0d

Asif, M., Searcy, C., Zutshi, A., \& Ahmad, N. (2011). An integrated management systems approach to corporate sustainability. European Business Review, 23(4), 353-367. http://dx.doi.org/10.1108/09555341111145744

Asif, M., Searcy, C., Zutshi, A., \& Fisscher, O. A. M. (2013). An integrated management systems approach to corporate social responsibility. Journal of Cleaner Production, 56, 77-17. http://dx.doi.org/10.1016/j.jclepro.2011.10.034

Asif, M., \& Searcy, C. (2014). Towards a standardised management system for corporate sustainable development. The TQM Journal, 26(5), 411-430. http://dx.doi.org/10.1108/TQM-08-2012-0057

Azapagic, A. (2003). Systems approach to corporate sustainability: A general management framework. Trans IChemE, 81(5), 303-316. http://dx.doi.org/10.1205/095758203770224342

Azapagic, A., \& Perdan, S. (2003). Managing corporate social responsibility: Translating theory into business practice. Corporate Environmental Strategy: International Journal of Corporate Sustainability, 10, 97-108. Retrieved from https://www.escholar.manchester.ac.uk/uk-ac-man-scw:103630

Castka, P., Bamber, C. J., Bamber, D. J., \& Sharp, J. M. (2004a). Integrating corporate social responsibility into ISO management systems - in search of a feasible CSR management system framework. The TQM Magazine, 16(3), 216-224. http://dx.doi.org/10.1108/09544780410532954

Castka, P., Bamber, C. J., \& Sharp, J. M. (2004b). Implementing Effective Corporate Social Responsibility and Corporate Governance-A Framework. London: British Standards Institution. Retrieved from http://www.the-hpo.com/downloads/CSR\%20Framework\%20Final.pdf

Cramer, P. (2005). Experiences with structuring CSR in Dutch industry. Journal of Cleaner Production, 13(6), 538-592. http://dx.doi.org/10.1016/j.jclepro.2003.12.008

Education Criteria for Performance Excellence. (2011). 2011-2012 Education Criteria for Performance Excellence. National Institute of Standards and Technology (NIST), Retrieved from http://www.ncate.org/ /media/Files/caep/accreditation-resources/baldridge-education-criteria.pdf

International Organization for Standardization. (2010). ISO 26000 Guidance on social responsibility. Geneva: International Organization for Standardization.

Klaver, J., \& Jonker, J. (2000). Changing corporate environmental management: Development of new $\begin{array}{lllll}\text { management systems. Eco-Management and Auditing, } & \text { 91-97. }\end{array}$ http://dx.doi.org/10.1002/1099-0925(200006)7:2\%3C91::AID-EMA127\%3E3.0.CO;2-J

Lewin, K. (1951). Field Theory in Social Science. New York, NY: Harper \& Brothers.

Liew, P. Y., \& Lütge, C. (2016). Integrated management system frameworks for corporate social responsibility and related concepts. Journal of Management and Sustainability, 6(3), 12-24. http://dx.doi.org/10.5539/jms.v6n3p12

Maas, S., \& Reniers, G. (2014). Development of a CSR model for practice: connecting five inherent areas of sustainable business. Journal of Cleaner Production, 64, 104-114. http://dx.doi.org/10.1016/j.jclepro.2013.07.039

MacDonald, J. P. (2005). Strategic sustainable development using ISO 14001 standard. Journal of Cleaner Production, 13, 631-643. http://dx.doi.org/10.1016/j.jclepro.2003.06.001 
Maignan, I., Ferrell, O. C., \& Ferrell, L. (2005). A stakeholder model for implementing social responsibility in $\begin{array}{llll}\text { marketing. } & \text { European Journal of Marketing, 39(9/10), 956-977. }\end{array}$ http://dx.doi.org/10.1108/03090560510610662

Maon, F., Lindgreen, A., \& Swaen, V. (2009). Designing and implementing corporate social responsibility: An integrative framework grounded in theory and practice. Journal of Business Ethics, 87, 71-89. http://dx.doi.org/10.1007/s10551-008-9804-2

McElhaney, K. A., Toffel, M. W., \& Hill, N. (Summer 2004). Designing a sustainability management system at BMW Group: The Designworks/USA Case Study. Greener Management International, 46, 103-116. https://doi.org/10.9774/GLEAF.3062.2004.su.00010

Moxen, J., \& Strachan, P. A. (2000). ISO 14001: a case of cultural myopia. Eco-Management \& Auditing, 7(2), 82-90. http://dx.doi.org/10.1002/1099-0925(200006)7:2\%3C82::AID-EMA128\%3E3.0.CO;2-E

Oktem, U., Lewis, P., Donovan, D., Hagan, J. R., \& Pace, T. (2004). EMS and sustainable development: A model and comparative studies of integration. Greener Management International, 46, 11-28. http://dx.doi.org/10.9774/GLEAF.3062.2004.su.00004

Panapanaan, V. M., Linnanen, L., Karvonen, M., \& Phan, V. T. (2003). Roadmapping corporate social responsibility in Finnish companies. Journal of Business Ethics, 44(2/3), 133-148. http://dx.doi.org/10.1023/A:1023391530903

Pojasek, R. B. (2005). Improving Processes: The traditional approach versus the systems approach. Environmental Quality Management, 15(1), 91-100. https://doi.org/10.1002/tqem.20071

Pojasek, R. B. (2012a). Quality toolbox: Planning a sustainability thrust for organizational governance. Environmental Quality Management, 21(4), 77-85. http://dx.doi.org/10.1002/tqem.21310

Pojasek, R. B. (2012b). Quality toolbox: Implementing a sustainability management system. Environmental Quality Management, 22(1), 83-90. http://dx.doi.org/10.1002/tqem.21319

Pojasek, R. B. (2012c). Quality toolbox: Checking and reviewing sustainability progress. Environmental Quality Management, 22(2), 83-91. http://dx.doi.org/10.1002/tqem.21328

Sealy, I., Wehrmeyer, W., France, C., \& Leach, M. (2010). Sustainable development management systems in global business organizations. Management Research Review, 33(11), 1083-1096. http://dx.doi.org/10.1108/01409171011085912

Singh, R. K., Murty, H. R., \& Gupta, S. K. (2007). An approach to develop sustainability management systems in the steel industry. World Review of Entrepreneurship, Management and Sustainable Development, 3(1), 90-108. http://dx.doi.org/10.1504/WREMSD.2007.012133

Werre, M. (2003). Implementing corporate responsibility: The Chiquita Case. Journal of Business Ethcs, 44(2/3), 247-260. http://dx.doi.org/10.1023/A:1023316303587

\section{Appendix A}

\section{An Overview of Management System Frameworks for CSR}

Table A1. An overview of management system frameworks for CSR that have a similar structure as the ISO-based management systems (adapted from the respective literature)

\begin{tabular}{|c|c|c|c|}
\hline $\begin{array}{l}\text { Author(s), } \\
\text { Year }\end{array}$ & Argandoña, 2004 & $\begin{array}{l}\text { Castka, C.J. Bamber, D.J. Bamber \& } \\
\text { Sharp, 2004 } \\
\text { Castka, C.J. Bamber \& Sharp, } 2004\end{array}$ & Azapagic \& Perdan, 2003 \\
\hline $\begin{array}{l}\text { Name of } \\
\text { Management } \\
\text { System }\end{array}$ & $\begin{array}{l}\text { Ethical, Social and Environmental Management } \\
\text { System (ESEMS) }\end{array}$ & $\begin{array}{l}\text { Corporate Social Responsibility and } \\
\text { Corporate Governance (CG) Management } \\
\text { System (CSR/CGMS) }\end{array}$ & $\begin{array}{l}\text { Corporate Social Responsibility Management } \\
\text { System (CSRMS) }\end{array}$ \\
\hline $\begin{array}{l}\text { Concise } \\
\text { Description of } \\
\text { Management } \\
\text { System }\end{array}$ & $\begin{array}{l}\text { The ESEMS framework is based on four pillars } \\
\text { (Design, Implement, Monitor and Act). The aim of } \\
\text { the ESEMS framework is to develop and sustain } \\
\text { ethical behavior in the organization, orienting it } \\
\text { towards corporate and ethical excellence. }\end{array}$ & $\begin{array}{l}\text { The CSR/CGMS framework is based on } \\
\text { two fundamental principles (systems } \\
\text { thinking and process management) and is } \\
\text { analogous to ISO } 9001: 2000 \text {. The aim of } \\
\text { the CSR/CGMS is to define, understand } \\
\text { and improve the balance between } \\
\text { entrepreneurship and ethical practice. }\end{array}$ & $\begin{array}{l}\text { This CSRMS is based on the familiar models } \\
\text { of total quality management and } \\
\text { environmental management system. The aim } \\
\text { of the CSRMS is to translate SD principles } \\
\text { into business practice, integrate sustainability } \\
\text { thinking into business strategy and improve } \\
\text { the triple bottom line. }\end{array}$ \\
\hline $\begin{array}{l}\text { Elements of } \\
\text { the } \\
\text { Management } \\
\text { System }\end{array}$ & $\begin{array}{l}\text { 1. Define the organization's activities. } \\
\text { 2. Identify the relevant stakeholders, the ethical } \\
\text { issues and potential impacts } \\
\text { 3. Define the organization's ethical } \\
\text { commitments/policies towards itself, relevant } \\
\text { stakeholders and the society }\end{array}$ & $\begin{array}{l}\text { General requirements of the CSR/CGMS } \\
\text { CG Principles } \\
\text { Documentation Requirements of } \\
\text { CSR/CGMS } \\
\text { Management and Board Responsibility } \\
\text { - CSR/CG Policy }\end{array}$ & $\begin{array}{l}\text { Stage } 1 \text { : Policy Development } \\
\text { - Identify stakeholders using a stakeholder } \\
\text { analysis } \\
\text { - Identify key sustainability issues through } \\
\text { stakeholder consultations and using the }\end{array}$ \\
\hline
\end{tabular}


4. Develop an ethical code of conduct and management manual in consultation with stakeholders

5. Select within the top management, an individual or body to ensure the compliance with the policies.

6. Identify processes that are affected by the ESEMS and the organization's ethical undertaking

7. Define specific objectives and actions that must be performed to ensure that the affected processes comply with the requirements of the ESEMS.

8. Plan that the specific objectives and actions can be performed effectively in a timely and appropriate manner.

9. Ensure the availability of the necessary resources and information (including training)

10. Perform the necessary actions to achieve the planned objectives

11. Determine the criteria and methods to ensure that the adopted solutions are maintained and effective.

12. Define a system to verify and measure the objectives, activities and results.

13. Implement internal and external audits

14. Review the system regularly to ensure that it fulfills its purpose and is effective.

15. Establish the necessary improvement measures to achieve the planned results and ensure the continuous improvement of the programmes.

16. Establish methods to inform stakeholders of the commitments and performance.

17. Foster personal commitment and (if necessary) demand that the requirements of the ESEMS be met.

18. Ensure that the outsourced processes comply with the requirements of the ESEMS.

\section{- Structure and Responsibility}

○ Responsibility and authority

- CSR/CG Representative

o Non management personnel

○ Legal compliance

- Communication

- Communication processes

- Disclosure

- Reporting

- Board/management review

- Training and competence

- Legal compliance

\section{Identification of}

stakeholders'expectations

- Inclusion process for stakeholders

- Identification of stakeholders

- Engagement of stakeholders

Strategic Planning

- Evaluation of stakeholders'expectations

- Evaluation of the impacts of the organization

- Identification, assessment and control of risk

- CSR/CG objectives, targets and indicators

- Board supervision

Managing the system, processes and

resources

- Managing the system

- Managing the CSR/CGMS's processes

- Managing the resources

Measurement and analysis

- Monitoring and measurement of the

CSR/CGMS's processes

- Internal audit (audit committee and

function)

- Independent audit

Managing change and ensuring

continual improvement

- Managing change

- Continual improvement of CSR/CGMS

- Corrective and preventive actions findings at the sectoral level.

- Define CSR Policy and align with business vision and strategy

Stage 2 : Planning

- Establish a baseline by using sustainability (economic, environmental, social and integrated) indicators

- Sustainability Strength, Weakness, Opportunities and Threats (SWOT) analysis

- Set targets and objectives that are relevant to key sustainability issues

Stage 3: Implementation

- Integrate CSR into business practice

- Measurement and monitoring

- Training, awareness raising and motivating

Stage 4: Communication

- Internal and external communication

Stage 5: Review and corrective actions

- Progress review and identification of actions for improvements

Table A2. An overview of other management system frameworks for CSR (adapted from the respective literature)

\begin{tabular}{lll}
\hline Author(s), Year & $\begin{array}{l}\text { Name of Management } \\
\text { System }\end{array}$ & Concise Description of Management System \\
\hline Maas \& Reniers, & Sustainability & This conceptual framework for the strategic integration of CSR is \\
Management System for & the following five building blocks that are connected in a circular \\
& CSR (named Sus5) & - Knowledge and commitment of management \\
& - Knowledge and commitment of stakeholders \\
& - Strategic planning \\
& - Knowledge and commitment of the workforce \\
& - Operational planning, implementation and monitoring
\end{tabular}

The operational information and performance results are subsequently channeled for management and stakeholder review. This framework goes beyond the limitations of the traditional PDCA cycle as it is built on interconnected soft and hard factors of CSR which represent the emotional and rational aspects of implementing CSR within an organization.

\begin{tabular}{ll}
\hline Aravossis, & Methodological \\
Panayiotou \& Tsousi, & Framework for CSR
\end{tabular}

The methodological framework for CSR is an iterative three stage framework and it is designed for the development and implementation of effective CSR programmes that can be adapted to the unique characteristics of each organization and sector.

- Stage 1 - CSR Analysis Stage: PEST (Political, Economical, Social and Technological) and SWOT (Strengths, Weakness, Opportunities and Threats) analyses are used to assess the potential external and internal factors that can affect the strategic orientation of the organization concerning CSR directly or indirectly. Based on these internal and external strategic analyses, missions are defined and specific measurable CSR targets that are coherent with the organizational culture and vision are set.

- Stage 2 - CSR Execution Stage: Specific CSR action plans and practices for five CSR evaluation categories (such as environment, community, human capital, shareholders and market place [customers and suppliers]) are formulated and executed in order to fulfil the set targets. An appointed CSR committee is responsible for the coordination of CSR actions in the different organizational units. Detailed instructions on how an action should be executed are provided through specific action plans.

- Stage 3 - CSR Evaluation Stage: The CSR performance of the organization is evaluated based on the five defined categories using a multicriteria analysis. Included in this analysis are weighted performance indicators that are related to the organization's impact on the five defined categories. In order to promote the continuous improvement of the system and CSR programmes, the results of the evaluation stage are channeled back to the CSR analysis stage for further assessment.

$\begin{array}{lll}\begin{array}{l}\text { Maon, Lindgreen \& } \\ \text { Swaen, }\end{array} & \begin{array}{l}\text { Integrative Framework for } \\ \text { 2009 }\end{array} & \begin{array}{l}\text { Based on Lewin's force field model of change, a similar concept to the PDCA cycle } \\ \text { (plan-do-check/improve-mainstream) and multiple case studies that involved multinationals from different } \\ \text { Implementing CSR }\end{array} \\ \text { business sectors, the authors identified four stages of organizational change (unfreeze, move, refreeze and }\end{array}$


sensitize) for the development and implementation of CSR. These four stages encompass the following nine key steps. Continuous stakeholder dialogue should also be conducted concurrently with these nine key steps.

- Raise CSR awareness within the organization

- Assess corporate purpose in its societal context (Uncovering organizational systems, corporate norms and values; Identifying key stakeholders and critical stakeholder issues)

- Establish a vision and working definition for CSR

- Assess current CSR status

(Audit current CSR norms, standards and practices, Benchmark competitors' CSR practices, norms, standards and practices)

- Develop an integrated CSR strategic plan

(Embed CSR in organizational strategy)

- Implement the integrated CSR strategic plan (Implement organizational initiatives and strategies linked to CSR)

- Communicate CSR commitments and performance (Internal and external communication)

- Evaluate integrated CSR strategies and communication (Evaluate, verify and report on CSR progress)

- Institutionalize CSR (Anchor changes into organizational systems, corporate culture and values)

\begin{tabular}{ll}
\hline Maignan, O.C. & A Stakeholder Model for \\
Ferrell \& & Implementing Social \\
L. Ferrell, 2005 & Responsibility in \\
& Marketing
\end{tabular}

This conceptual model aims to provide a well-balanced and integrated stakeholder oriented approach for the implementation and management of CSR in marketing. This approach broadens the scope of marketing from customer oriented to stakeholder oriented and it has the following key steps:

- Step 1: Identify the organizational norm and values that are likely to have implications for CSR.

- Step 2: Identify the relevant stakeholders and assess their power, legitimacy and urgency. The level of power and legitimacy of the stakeholders determines the degree of urgency in addressing their needs.

- Step 3: Identify the relevant stakeholder issues.

- Step 4: Define the meaning of CSR that specifically fits the organization.

- Step 5: Audit current practices to identify the practices that the organization already has in place to address the important stakeholder issues as well as to identify which practices need to be added or improved.

- Step 6: Implement CSR initiatives with consideration of two main criteria (level of financial and organizational investments as well as urgency)

- Step 7: Promote CSR by creating awareness of CSR and by involvement/engagement of stakeholders

- Step 8: Obtain stakeholder feedback/assessment of the organization's performance and progress in addressing the stakeholder issues. In order to continuously improve and keep abreast of the evolving stakeholder issues, the stakeholder feedbacks/assessment are channeled back to Step 5 for the assessment of short term progress as well as channeled back to Step 1, 2 and 3 for the reassessment of these three steps to determine their suitability on long term basis.

$\begin{array}{ll}\text { Panapanaan, } & \text { Conceptual Framework } \\ \text { Linnanen, Karvonen } & \text { for managing CSR }\end{array}$

\& Phan, 2003
This conceptual framework for CSR was developed based on an empirical study of how CSR is internalized and managed in Finnish companies This framework reflect the main CSR management areas but does not fully reflect the corporate reality and therefore it needs to be tested. The framework has three main steps and could be used as a guide for streamlining and managing CSR.

- Step 1: Social Risk Assessment is adopted to identify and assess the main CSR issues and parameters that are relevant to the organization as well as the organization's current position, problems and management prospects with regard to CSR. As the authors viewed CSR as the social dimension of sustainable development, this assessment concentrates on CSR issues that are related to only four groups of stakeholders such as employees, community, suppliers and customers.

- Step 2: Decision Making. Based on the findings of the Social Risk Assessment, a decision will be made whether to proceed with the management of CSR or not.

- Step 3: CSR Management. If the decision is yes, a management approach that encompasses the following five sequential activities can be adopted for the management of CSR. An important aspect of this management approach is the over-arching principle and commitment to continuous improvement and constant communication.

$\circ \quad$ organization and structure,

planning,

implementation,

monitoring and evaluation

communication and reporting.

\begin{tabular}{|c|c|c|}
\hline Werre, 2003 & $\begin{array}{l}\text { Corporate Responsibility } \\
\text { Implementation Model }\end{array}$ & $\begin{array}{l}\text { The CR Implementation model consists of four implementation phases. All four phases must be covered in order } \\
\text { to achieve a lasting organizational change. } \\
\text { - Phase 1: Raising top management awareness } \\
\text { The first implementation phase focuses on raising the awareness of the top management on core values with } \\
\text { regard to CR as well as on the key developments in the external environment of the organization that can } \\
\text { influence the survival of the organization. } \\
\text { - Phase 2: Formulating a CR vision and core corporate values } \\
\text { The second implementation phase requires the top management to formulate a clear CR vision (long term } \\
\text { strategic goals and the desired change of the organization) and core corporate values (decision and behavior } \\
\text { guiding principles to support the organization in reaching its CR goals and vision). In this phase, it is } \\
\text { important to reach the required fit between the corporate values and personal values of employees for a } \\
\text { successful implementation of CR. } \\
\text { - Phase 3: Changing organizational behavior and } \\
\text { - Phase 4: Anchoring change } \\
\text { The third phase is about creating a large scale change in organizational behavior that is in line with the defined } \\
\text { vision and core values. This is followed by the final phase that focuses on maintaining this organizational } \\
\text { change. However, there is no clear distinction between the implementation actions of these two phases as } \\
\text { many of the implementation actions for both phases have an impact on both creating and anchoring change. } \\
\text { Management system that is based on the Plan-Do-Check-Adapt cycle is recommended for translating the CR } \\
\text { vision and core values into concrete actions to implement and anchor CR in the organization. }\end{array}$ \\
\hline
\end{tabular}




\section{Appendix B}

\section{An Overview of Management System Frameworks for CS and SD}

Table B1. An overview of management system frameworks for CS and SD that have a similar structure as the ISO-based management systems (adapted from the respective literature)

\begin{tabular}{|c|c|c|c|c|}
\hline $\begin{array}{l}\text { Author(s), } \\
\text { Year }\end{array}$ & Asif \& Searcy, 2014 & Pojasek, 2012 & Singh, Murty \& Gupta, 2007 & Azapagic, 2003 \\
\hline $\begin{array}{l}\text { Name of } \\
\text { Management } \\
\text { System }\end{array}$ & $\begin{array}{l}\text { Sustainable Development } \\
\text { Management System (SDMS) }\end{array}$ & $\begin{array}{l}\text { Sustainability Management } \\
\text { System (SMS) }\end{array}$ & $\begin{array}{l}\text { Sustainability Management System } \\
\text { (SMS) }\end{array}$ & $\begin{array}{l}\text { Corporate Sustainability } \\
\text { Management System (CSMS) }\end{array}$ \\
\hline $\begin{array}{l}\text { Concise } \\
\text { Description of } \\
\text { Management } \\
\text { System }\end{array}$ & $\begin{array}{l}\text { This SDMS consists of three } \\
\text { interrelated parts: underlying values } \\
\text { and principles of sustainability; } \\
\text { requirements for a PDCA based } \\
\text { management system and the } \\
\text { assessment of management system } \\
\text { through hybrid approach. It aims to } \\
\text { provide a systematic and balanced } \\
\text { approach for the management of the } \\
\text { triple bottom line. }\end{array}$ & $\begin{array}{l}\text { This SMS aims to help } \\
\text { organizations in the continuous } \\
\text { improvement of their ability to } \\
\text { manage sustainability related } \\
\text { operational, regulatory and } \\
\text { reputational risks. }\end{array}$ & $\begin{array}{l}\text { The SMS is in line with the ISO } \\
9001 \text {, ISO } 14001 \text { and SA } 8000 \\
\text { standards. It is developed for the } \\
\text { steel industry and it aims to } \\
\text { integrate sustainability } \\
\text { considerations into the decision } \\
\text { making processes of a steel } \\
\text { company. }\end{array}$ & $\begin{array}{l}\text { The CSMS was developed in } \\
\text { collaboration with the industry and } \\
\text { is compatible with TQM and EMS. } \\
\text { It aims to translate SD principles } \\
\text { into business practice and help } \\
\text { improve the triple bottom line }\end{array}$ \\
\hline $\begin{array}{l}\text { Elements of } \\
\text { the } \\
\text { Management } \\
\text { System }\end{array}$ & 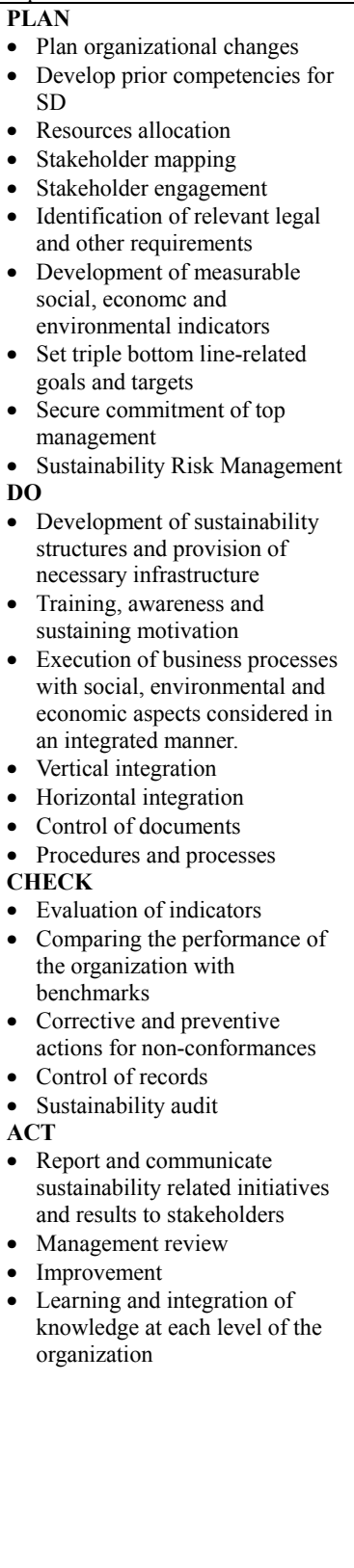 & 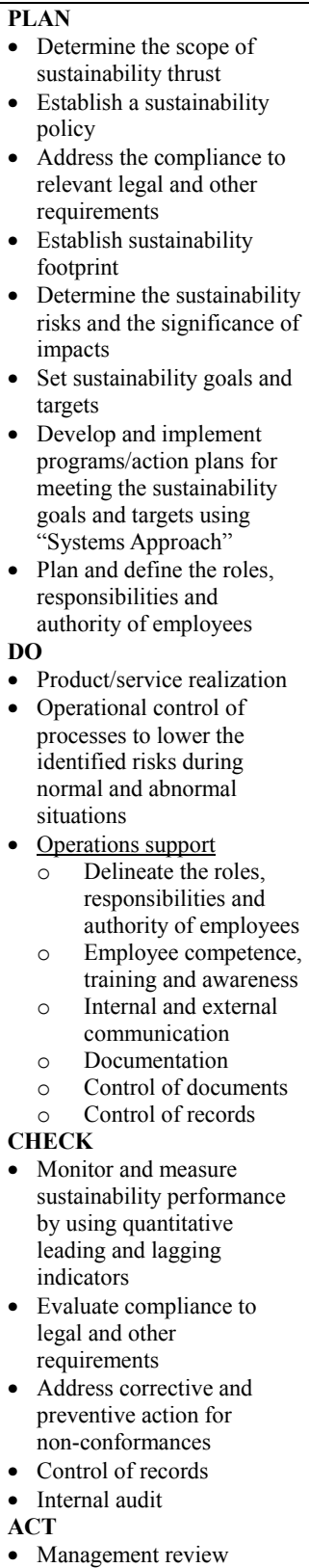 & 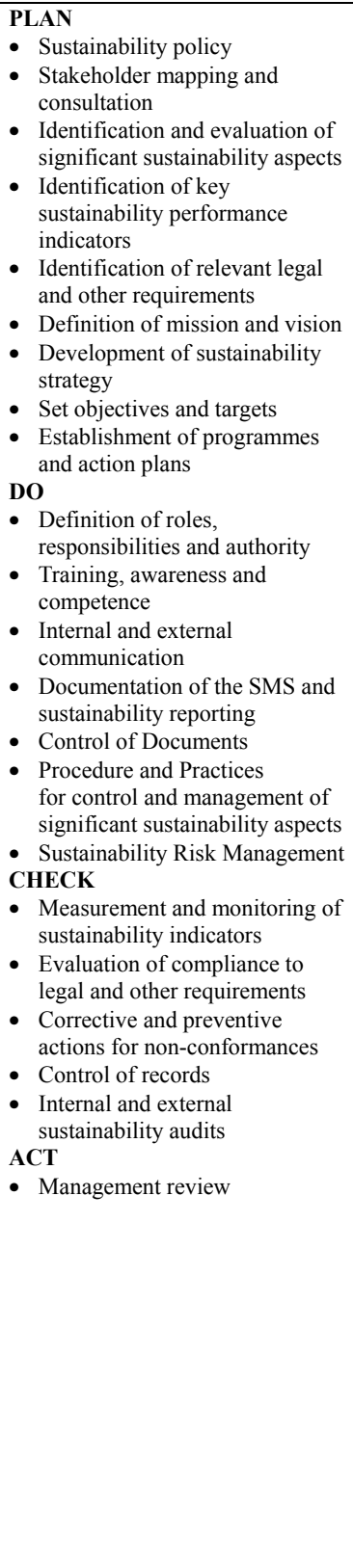 & 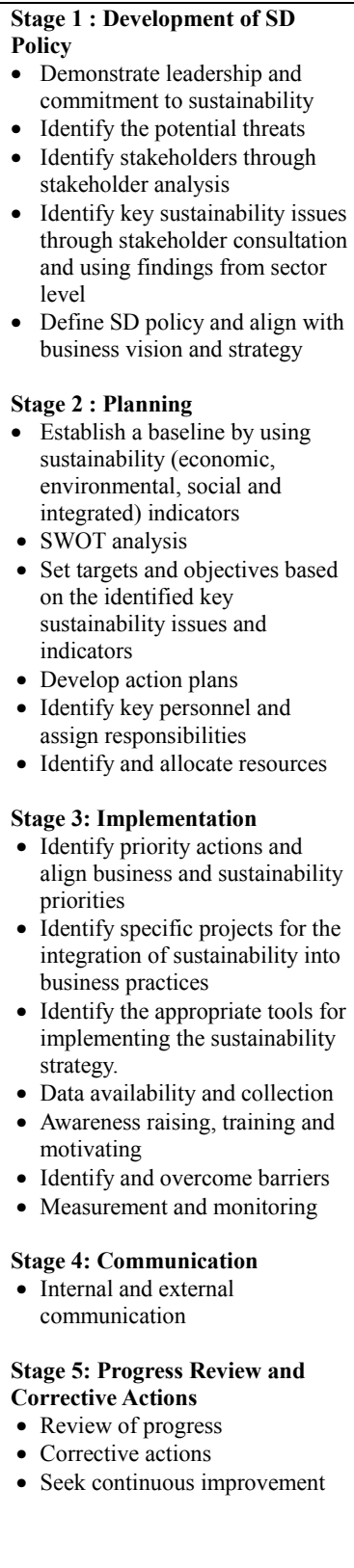 \\
\hline
\end{tabular}


Table B2. An overview of other management system frameworks for CS and SD (adapted from the respective literature).

\begin{tabular}{|c|c|c|}
\hline $\begin{array}{l}\text { Author(s), } \\
\text { Year }\end{array}$ & $\begin{array}{l}\text { Name of Management } \\
\text { System }\end{array}$ & Concise Description of Management System \\
\hline $\begin{array}{l}\text { MacDonald, } \\
2005\end{array}$ & $\begin{array}{l}\text { Strategy sustainable } \\
\text { development using ISO } \\
14001\end{array}$ & $\begin{array}{l}\text { The proposed strategic planning framework for ISO } 14001 \text { standard has the following } 15 \text { clauses and these clauses } \\
\text { encompass the minimum requirements for a more sustainable business model. } \\
\text { - Identification of environmental aspects } \\
\text { - Identification of social aspects } \\
\text { - Determination of significant environmental and social aspects } \\
\text { - Articulation of core values and purpose } \\
\text { - Envision of a sustainable organization } \\
\text { - Creation of a sustainability policy } \\
\text { - Creation of ultimate objectives and interim targets } \\
\text { - Strategy development } \\
\text { - Barrier identification } \\
\text { - Strategy testing } \\
\text { - Action development } \\
\text { - Indicator development } \\
\text { - Tool selection } \\
\text { - Sustainability program development } \\
\text { - Identification of legal and other requirements }\end{array}$ \\
\hline $\begin{array}{l}\text { Oktem, Lewis, } \\
\text { Donovan, } \\
\text { Hagan \& Pace, } \\
2004\end{array}$ & $\begin{array}{l}\text { Sustainable Management } \\
\text { System (SMS) }\end{array}$ & $\begin{array}{l}\text { The SMS model was developed for the integration of environment, health and safety and sustainable development into } \\
\text { business systems. This model is based on environmental management system principles and has the following five main } \\
\text { components. } \\
\text { - Develop a business case for SMS to obtain management buy-in } \\
\text { - Organizational component } \\
\text { Once the management arrives at the understanding of the need for a SMS, there is an appropriate seat at the senior } \\
\text { management level for EHS and SD. A clear organization structure and the provision of other resources (human } \\
\text { resources, financial resources, specialized skills and technology) are the focus of this component. } \\
\text { - Operational component } \\
\text { The operational component of this model covers the core elements of the management system framework (ranging } \\
\text { from setting of policy, objectives and targets, integration of EHS and SD elements into business objectives and } \\
\text { corporate strategy to training and awareness of employees/contractors/suppliers, documentation, document/record } \\
\text { control as well as internal and external communication). The scope of SMS must be extended to the organization's } \\
\text { supply chain. } \\
\text { - Enterprise resource planning (ERP) / Information Technology (IT) } \\
\text { A well designed ERP system ( a category of business management software) on an IT platform can be useful in } \\
\text { supporting the processes of a SMS as it is able to provide an integrated overview of the business processes (for both } \\
\text { the organization and its supply chain) and facilitate data collection, management and interpretation. } \\
\text { Monitoring and audits } \\
\text { This component covers elements such as auditing of the SMS, management of non-conformances, corrective and } \\
\text { preventive actions, accident and emergency management. }\end{array}$ \\
\hline $\begin{array}{l}\text { McElhaney \& } \\
\text { Toffel, } 2004\end{array}$ & $\begin{array}{l}\text { Sustainability } \\
\text { Management System } \\
\text { (SMS) }\end{array}$ & $\begin{array}{l}\text { A case study on how an organization developed and implemented a SMS from an ISO } 14001 \text { environmental management } \\
\text { system. The SMS extends beyond the ISO } 14001 \text { 's environmental scope and includes social and economic aspects. The } \\
\text { five implementation phases of the SMS are as follows : } \\
\text { - Phase 1: Create a sustainability policy } \\
\text { - Phase 2: Identify and prioritize economic, environmental and social aspects and impacts } \\
\text { - Phase 3: Establish objectives and targets } \\
\text { - Phase 4: Develop programmes to achieve objectives and targets } \\
\text { - Phase 5: Evaluate progress via periodic internal audits and management reviews. }\end{array}$ \\
\hline $\begin{array}{l}\text { Klaver \& } \\
\text { Jonker, 2000 }\end{array}$ & $\begin{array}{l}\text { New Environmental } \\
\text { Management System } \\
\text { (NEMS) }\end{array}$ & $\begin{array}{l}\text { The new EMS must meet the following eight requirements: } \\
\text { - Monitor changes in society and the (re)actions of key stakeholders } \\
\text { - The interpretation of the monitoring results should be discussed between strategic management and stakeholders } \\
\text { - Redefine target areas for corporate (environmental) strategy to include the management of other social and } \\
\text { environmental aspects that are gaining importance. } \\
\text { - Reformulate mission statement to include commitment towards sustainable development and wider social } \\
\text { responsibilities } \\
\text { - Adopt other approaches to reduce the uncertainty of ecological risk and the subjectively perceived social threats which } \\
\text { cannot be reduced by the usual environmental management approaches. } \\
\text { - Develop new ways of consensus building between strategic management and employees about the necessary and } \\
\text { desired organizational changes } \\
\text { - Manage the value differences that arise in the organization, between organizations as well as with key stakeholders of } \\
\text { the organization. } \\
\text { - Choose a suitable implementation strategy that fits to the existing organization. }\end{array}$ \\
\hline
\end{tabular}

\section{Copyrights}

Copyright for this article is retained by the author(s), with first publication rights granted to the journal.

This is an open-access article distributed under the terms and conditions of the Creative Commons Attribution license (http://creativecommons.org/licenses/by/4.0/). 